\title{
Analysis of the Lacl Family Regulators of Erwinia chrysanthemi 3937, Involvement in the Bacterial Phytopathogenicity
}

\author{
Frédérique Van Gijsegem, ${ }^{1}$ Aleksandra Wlodarczyk, ${ }^{2}$ Amandine Cornu, ${ }^{2}$ Sylvie Reverchon, ${ }^{2}$ and \\ Nicole Hugouvieux-Cotte-Pattat ${ }^{2}$ \\ ${ }^{1}$ Laboratoire Interactions Plantes Pathogènes, UMR217 INRA/AgroParisTech/UPMC Univ Paris 6, 16 rue Claude Bernard, \\ 75231 Paris, Cedex 05, France; ${ }^{2}$ Univ Lyon, F-69622, Lyon, Université Lyon 1 Villeurbanne, INSA de Lyon F-69621 \\ Villeurbanne, CNRS UMR5240 Microbiologie Adaptation et Pathogénie, bat Lwoff, 10 rue Dubois, Domaine Scientifique \\ de la Doua, 69622 Villeurbanne Cedex, France
}

Submitted 29 February 2008. Accepted 26 June 2008.

\begin{abstract}
Analysis of the regulators of the LacI family was performed in order to identify those potentially involved in pathogenicity of Erwinia chrysanthemi (Dickeya dadantii). Among the 18 members of the LacI family, the function of 11 members is either known or predicted and only 7 members have, as yet, no proposed function. Inactivation of these seven genes, called $l f a R, l f b R, l f c R, l f d R, l f e R, l f f R$, and $l f g R$, demonstrated that four of them are important for plant infection. The $l f a R$ and $l f c R$ mutants showed a reduced virulence on chicory, Saintpaulia sp., and Arabidopsis. The lfeR mutant showed a reduced virulence on Arabidopsis. The lfdR mutant was more efficient than the wild-type strain in initiating maceration on Saintpaulia sp. The genetic environment of each regulator was examined to detect adjacent genes potentially involved in a common function. Construction of transcriptional fusions in these neighboring genes demonstrated that five regulators, LfaR, LfcR, LfeR, LffR, and LfgR, act as repressors of adjacent genes. Analysis of these fusions also indicated that the genes controlled by $L f a R$, LfcR, LfgR, and LffR are expressed during plant infection. Moreover, addition of crude plant extracts to culture medium demonstrated that the expression of the LfaR- and LfgR-controlled genes is specifically induced by plant components.
\end{abstract}

Additional keywords: induction, in planta expression, regulation.

Pectinolytic enterobacteria produce soft-rot disease on many plant species. The disease is characterized by the maceration of plant tissue as the result of the action of a set of enzymes degrading the plant cell wall. Among these enzymes, pectatelyases, which depolymerise pectin, play an essential role in pathogenicity (Hugouvieux-Cotte-Pattat et al. 1996). Although essential, the synthesis and secretion of pectate lyases are not the sole factors necessary for bacterial virulence. Plant colonization is a multifactorial process involving numerous additional factors. Moreover, fine tuning is required for the production of the virulence factors at the right time and level during

Corresponding author: N. Hugouvieux-Cotte-Pattat; Telephone: +33-47243-1553; Fax: +33-472-43-1584; E-mail: Nicole.Cotte-Pattat@insa-lyon.fr

Current address of N. Hugouvieux-Cotte-Pattat: Microbiologie Adaptation et Pathogénie. infection. Bacterial pathogenesis includes steps wherein the partners recognize each other and respond accordingly by modulating the expression of specific sets of genes. The completion of the Erwinia chrysanthemi (or Dickeya dadantii) 3937 genome provide a genome-scale view of the metabolic capacities of this plant-pathogenic bacterium (J. D. Glassner and N. T. Perna unpublished data). A substantial part of the $E$. chrysanthemi genome is dedicated to genes involved in regulation. Nearly 9\% of strain 3937 predicted proteins (approximately 400 proteins) are thought to play a role in transcriptional regulation, and 293 of these proteins are predicted to be DNA-binding transcriptional regulators. Approximately 20\% of strain 3937 transcriptional regulators display similarity with regulators found only in plant-associated bacteria, such as Ralstonia spp., Pseudomonas syringae, Agrobacterium spp., Xanthomonas spp., or Rhizobium spp.. Such regulators could be implicated in responses to conditions specifically encountered in the plant tissues. Strain 3937 transcriptional regulators are distributed in 28 distinct families containing from 1 to 62 members. As observed in other enterobacteria, the LysR family is the largest family of transcriptional regulators in E. chrysanthemi, with 62 members. The two-component response regulators are represented by 30 members. The LacI family is quite well represented, with 18 members, compared with 14 in Escherichia coli K-12 and Erwinia carotovora subsp. atroseptica (Bell et al. 2004).

Among the numerous E. chrysanthemi regulators, only a few have been shown to be involved in the control of virulence factors. The correct production of pectate lyases, the major maceration factors, is directed by a regulatory network including mostly repressors of various families (Hugouvieux-CottePattat et al. 1996; Sepulchre et al. 2007). KdgR, a repressor of the IclR family, mediates induction of several genes involved in pectin degradation or related functions (Reverchon et al. 1991; Rodionov et al. 2004). PecS, a repressor of the MarR family, controls production of plant cell-wall-degrading enzymes and of a blue pigment, indigoidine, which could act as antioxydant (Reverchon et al. 1994, 2002). PecT, a repressor of the LysR family, controls pectate lyase and exopolysaccharide synthesis (Surgey et al. 1996). The positive regulator CRP was found to be the major activator of pectate lyase synthesis (Reverchon et al. 1997). Recently, the GacA-GacS two-component system was shown to be important for activation of $E$. chrysanthemi virulence factors (Lebeau et al. 2008; Yang et al. 2008). 
Our aim was to use a functional approach on a whole family of E. chrysanthemi regulators. The LacI family was chosen for the present work. The regulators of the LacI family are often involved in the control of degradative pathways. They directly interact with DNA, frequently by a negative effect, acting as repressors in the absence of the inducing compound (Lewis 2005). Among the 18 regulators of the LacI family found in $E$. chrysanthemi, 7 have a totally unknown function. We analyzed the potential involvement of these LacI family regulators in the interaction with the plant hosts. This study was performed by i) systematic mutagenesis of each gene encoding a LacI family regulator to establish their role in virulence and ii) construction of genetic fusions in adjacent genes, taken as potential regulated targets, to assess their expression during plant infection.

\section{RESULTS}

The regulators of the LacI family in E. chrysanthemi.

The E. chrysanthemi 3937 genome encodes 18 potential transcriptional regulators of the LacI family. Homologs of these regulators were identified by Blast searches. The best identity score was found in 10 cases with E. carotovora, in 4 cases with Yersinia spp., in 2 cases with Salmonella spp. and in the 2 last cases with the nonenterobacterial genera Chromobacterium and Rhizobium (Table 1). Eight of these regulators are conserved in Escherichia coli K-12 (Table 1) and their function has been clearly determined in this species. CytR, FruR, GalR, GalS, GntR, LacI, RbsR, and PurR are involved in the catabolism of nucleosides, fructose, galactose, galactosides, gluconate, lactose, and ribose and in the biosynthesis of purine, respectively. In the case of these eight regulators, we hypothesized that their function is conserved in Erwinia chrysanthemi. In addition, the role of the two regulators RafR and ScrR, which are encoded by genetic mobile elements, was described in various enterobacteria (Aslanidis et al. 1989; Titgemeyer et al. 1996). They are involved in the catabolism of raffinose and sucrose, respectively, and these functions were confirmed in E. chrysanthemi (unpublished data). ID 18202, encoding the GanR regulator, is situated in a cluster of genes which was recently shown to be involved in galactan degrada- tion (Delangle et al. 2007). Thus, there are still seven E. chrysanthemi regulators of the LacI family which do not yet have a known function.

We decided to perform a systematic analysis of these seven $E$. chrysanthemi regulators. To facilitate this analysis, we arbitrarily allocated a name to each of these genes or proteins and to certain adjacent genes (Tables 1 and 2; Fig. 1). The LacI family regulators were named LfaR (ID 15303), LfbR (ID 16819), LfcR (ID 18397), LfdR (ID 18466), LfeR (ID 18558), LffR (ID 18801), and LfgR (ID 19202). A systematic mutagenesis was carried out to determine the importance of these E. chrysanthemi regulators in the plant-bacteria interaction. A chloramphenicol-resistant $\left(\mathrm{Cm}^{\mathrm{r}}\right)$ cassette was inserted into the cloned genes and, using reverse genetics, these insertions were integrated in the chromosome of the wild-type strain 3937. Hence, we were able to obtain mutants affected for each regulator.

\section{Virulence of the regulator mutants.}

We first compared the maceration on chicory leaves provoked by each mutant $24 \mathrm{~h}$ postinfection with that caused by the parental strain 3937 (Fig. 2). There was no significant difference in the degree of maceration caused by the mutants $l f b R$, lfdR, $l f e R$, lffR, and $l f g R$. In contrast, the $l f a R$ and $l f c R$ mutants caused a clearly reduced maceration (Fig. 2). This result showed that the integrity of the regulators LfaR and LfcR is important for the development of soft-rot disease.

The pathogenicity of these mutants was also tested on two types of whole plants: Saintpaulia ionantha (African violet), the host plant from which strain 3937 has been isolated, and the plant model Arabidopsis thaliana, for which the pathosystem has been recently established (Dellagi et al. 2005). Saintpaulia sp. inoculations were performed by infiltration using a bacterial suspension at $10^{8}$ bacteria/ml (Fig. 3A). There was no difference in symptoms caused by the wild-type strain and the mutants affected for $l f b R$, $l f f R$, and $l f g R(P>0.3)$ (Fig. 3A). A repetitive but only slight delay in symptom occurrence was observed with the lfeR mutant $(P \approx 0.1)$ (Fig. 3A). In contrast, the $l f a R$, lfcR, and $l f d R$ mutants behaved significantly differently from the wild-type strain. The $l f a R$ mutant was able to initiate

Table 1. Eighteen regulators of the LacI family encoded by the 3937 genome and their homologues

\begin{tabular}{|c|c|c|c|c|}
\hline \multirow[b]{2}{*}{ ID no. } & \multirow[b]{2}{*}{ Name } & \multicolumn{2}{|c|}{ Identity with $(\%)^{a}$} & \multirow[b]{2}{*}{ Other bacteria spp. ${ }^{c}$} \\
\hline & & Escherichia coli $^{\mathrm{b}}$ & Erwinia carotovora & \\
\hline 18277 & FruR & 89 & 89 & $\underline{90}$ Yersinia, 89 Salmonella \\
\hline 14676 & PurR & 80 & $\underline{92}$ & 86 Yersinia, 86 Photorhabdus \\
\hline 18375 & GalS & 76 & $(\overline{56} \mathrm{GalR})$ & $\underline{77}$ Salmonella \\
\hline 18477 & GalR & 75 & 71 & $\overline{77}$ Yersinia, 75 Salmonella \\
\hline 15046 & GntR & 72 & 69 & $\overline{72}$ Yersinia, 72 Salmonella \\
\hline 18142 & RbsR & 69 & $\underline{83}$ & 70 Salmonella, 69 Photorhabdus \\
\hline 20411 & CytR & 66 & $\underline{74}$ & 68 Yersinia, 66 Salmonella \\
\hline 15766 & LacI & 55 & $\underline{62}$ & \\
\hline 19140 & RafR & $55^{\mathrm{d}}$ & $\underline{59}$ & 55 Yersinia \\
\hline 16544 & ScrR & $62^{\mathrm{d}}$ & $\underline{84}$ & 66 E. amylovora, 64 Klebsiella, 62 Salmonella \\
\hline 18202 & GanR & (42 LacI) & (47 LacI) & $\underline{85}$ Yersinia \\
\hline 15303 & LfaR & $52^{\mathrm{d}}$ & $\underline{67}$ & $\overline{57}$ Yersinia \\
\hline 18466 & LfdR & $(46 \mathrm{AscG})$ & $\overline{71}$ & 62 Salmonella \\
\hline 19202 & LfgR & $\ldots$ & $\underline{78}$ & 40 Rhizobium, 39 Agrobacterium \\
\hline 18801 & LffR & $\ldots$ & $\underline{75}$ & 60 Mannheimia, 41 Thermoanaerobacter, 40 Oceanobacillus, 37 Bacillus \\
\hline 18558 & LfeR & $\ldots$ & 67 & 76 Salmonella, 48 Ralstonia, 39 Streptomyces, 37 Pseudomonas, 35 Agrobacterium \\
\hline 18397 & LfcR & (31 ScrR) & (29 ScrR) & $\overline{35}$ Chromobacterium, 31 Vibrio \\
\hline 16819 & LfbR & $\ldots$ & (32 ECA4246) & $\underline{34}$ Rhizobium \\
\hline
\end{tabular}

${ }^{a}$ The best score is underlined. The level of identity with homologues known to be involved in a different pathway is shown in brackets parentheses, with the name of the corresponding homologue.

${ }^{\mathrm{b}}$ Escherichia coli $\mathrm{K} 12$ and other E. coli or Shigella strains.

${ }^{\mathrm{c}}$ The genus is indicated for bacteria encoding an homologous protein with an identity score superior or equal to the score obtained for $E$. coli proteins.

${ }^{\mathrm{d}}$ RafR and ScrR genes are encoded by mobile genetic elements, either plasmids or transposons. An LfaR homologue is found in a genomic island of an extraintestinal avian pathogenic $E$. coli strain. 
symptoms at the same frequency as the wild-type strain but symptom progression was delayed and less severe $(P<0.05)$. The $l f c R$ mutant was greatly affected in virulence because, compared with the wild-type strain, fewer inoculated plants exhibited symptoms and a delay in symptom progression was observed $(P<0.05)$. Compared with the wild-type strain, the lfdR mutant developed more rapidly severe symptoms (for example, 3 days postinoculation, $P=0.01$ ) (Fig. $3 \mathrm{~A}$ ). This was even more visible when a low inoculum was used (bacterial suspension at $10^{7}$ bacteria/ml, $P<0.04$ ) (Fig. 3B), a condition in which the wild-type strain was moderately efficient in symptom development (Fig. 3B).

On Arabidopsis, a decreased virulence was also observed with the $l f a R$ and $l f c R$ mutants (Fig. 4). The $l f a R$ mutant produced delayed and reduced symptoms $(P<0.05)$ and the $l f_{c} R$ mutant was impaired both in symptom occurrence and symptom severity $(P<0.05)$. Although the $l f e R$ mutant was weakly affected on Saintpaulia spp., it was clearly impaired in disease symptom progression on Arabidopsis $(P<0.05)$ (Fig. 4). Thus, on whole plants, the integrity of the regulators LfaR, LfcR, and LfeR is important for the development of soft-rot disease.

Bacterial growth in planta is also a parameter of bacterial virulence (Lebeau et al. 2008; Yang et al. 2008). Bacterial numerations were performed $24 \mathrm{~h}$ after inoculation of Arabidopsis leaves with the wild-type strain or the $l f a R, l f c R, l f d R$, and $l f e R$ mutants. At this time point, maceration symptoms are not yet observed, and it was shown that the bacterial population reaches a level of approximately $10^{5}$ bacteria per leaf, a level that remains stable as long as no rotting occurs (Lebeau

Table 2. Proteins encoded by the Erwinia chrysanthemi genomic clusters including a LacI regulator gene

\begin{tabular}{|c|c|c|}
\hline ID no. & Name & Protein description $^{\mathrm{a}}$ \\
\hline 20045 & LfaA & $\begin{array}{l}\text { Putative } \alpha \text {-glycosidase, of glycoside } \\
\text { hydrolase family } 31\end{array}$ \\
\hline 20044 & & MFS, anion:cation symporter \\
\hline 16820 & LfbE & Putative metal-dependent hydrolase \\
\hline 16821 & $\ldots$ & $\mathrm{ABC}$ transporter, ATPase \\
\hline 16822 & $\ldots$ & $\mathrm{ABC}$ transporter, membrane protein \\
\hline 16823 & $\ldots$ & $\mathrm{ABC}$ transporter, membrane protein \\
\hline 16824 & LfbB & $\begin{array}{l}\mathrm{ABC} \text { transporter, sugar periplasmic } \\
\text { binding protein }\end{array}$ \\
\hline 18391 & LfcK & Putative carbohydrate kinase \\
\hline 18392 & $\ldots$ & Hypothetical protein \\
\hline 18394 & $\ldots$ & Putative lyase or synthase \\
\hline 18395 & $\ldots$ & Hypothetical protein \\
\hline 18396 & $\ldots$ & MSF, metabolite: $\mathrm{H}^{+}$symporter \\
\hline 18467 & $\ldots$ & PTS, component IIA \\
\hline 18469 & $\ldots$ & PTS, component IIC \\
\hline 18471 & LfdP & $\begin{array}{l}\text { Putative phospho- } \beta \text {-glucosidase, of } \\
\text { glycoside hydrolase family } 1\end{array}$ \\
\hline 18472 & & PTS, component IIB \\
\hline 18557 & LfeW & Putative racemase or enolase \\
\hline 18805 & $\ldots$ & Putative isomerase \\
\hline 18804 & & MFS, nucleoside $\mathrm{H}^{+}$symporter \\
\hline 18803 & LffE & $\begin{array}{l}\text { Putative enzyme, 27\% identity with IolE } \\
\text { (Yoshida et al. 2004) }\end{array}$ \\
\hline 18802 & $\ldots$ & $\begin{array}{l}\text { Putative oxidoreductase, } \mathrm{Gfo} / \mathrm{Idh} / \mathrm{MocA} \\
\text { family }\end{array}$ \\
\hline 18800 & $\ldots$ & Hypothetical protein \\
\hline 19204 & $\ldots$ & $\mathrm{ABC}$ transporter, membrane protein \\
\hline 09205 & $\ldots$ & $\mathrm{ABC}$ transporter, membrane protein \\
\hline 09206 & & $\mathrm{ABC}$ transporter, ATPase \\
\hline 19207 & $\operatorname{LfgN}$ & $\begin{array}{l}\text { Putative enzyme, } 44 \% \text { identity with } \\
\text { RhiN (Hugouvieux-Cotte-Pattat 2004) }\end{array}$ \\
\hline 19208 & $\ldots$ & Hypothetical protein \\
\hline 19212 & $\ldots$ & $\begin{array}{l}\mathrm{ABC} \text { transporter, periplasmic binding } \\
\text { protein }\end{array}$ \\
\hline
\end{tabular}

${ }^{a}$ MFS, major facilitator superfamily; PTS, phosphoenolpyruvate-dependent phosphotransferase system; ABC, ATP binding cassette. et al. 2008). With the lfaR mutant, the bacterial population per leaves appeared 6- to 40-fold lower than that obtained with the wild-type strain $(P<0.0001)$. This alteration in bacterial growth in the early stages of infection suggests that the lfaR mutant is affected for adaptation to the plant environment.

\section{Effect of the regulator mutations on adjacent structural genes.}

Because the targets of a regulator are frequently found in the vicinity of its gene, we analyzed the genetic environment of the seven selected regulator genes (Fig. 1). They are all adjacent to or included in predicted operonic structures encoding both potential enzymes and transport systems (Fig. 1; Table 2). In most cases, these groups of genes are at least partially conserved in the vicinity of the orthologous regulator gene in other bacteria (data not shown). Such a global conservation suggested the occurrence of sets of genes involved in a common function. To test whether these adjacent conserved genes are potential targets of the regulator, we constructed transcriptional fusions in one gene of each cluster. Such fusions were obtained by insertion of uidA-Km cassettes in the structural genes $l f a A, l f b B$, lfcK, lfdP, lfeW, lffE, and $l f g N$ (Fig. 1; Table 2).

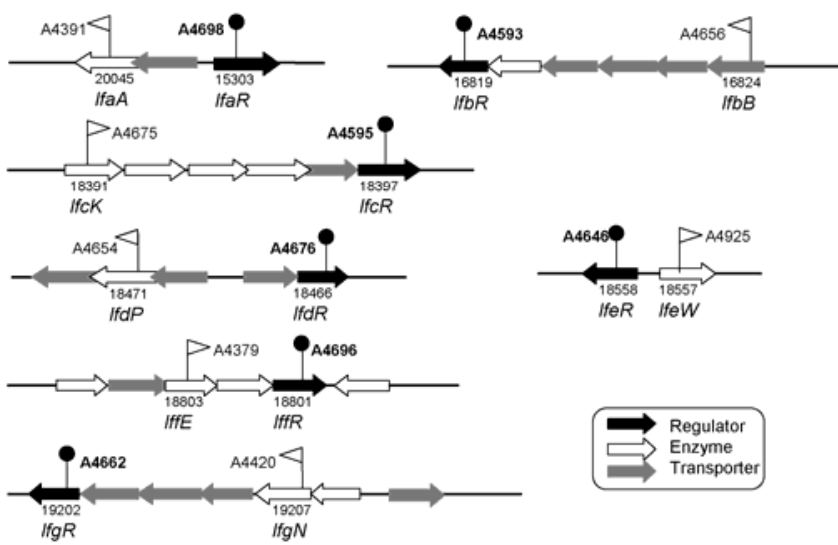

Fig. 1. Genetic organization of the Erwinia chrysanthemi clusters encoding the regulators of the LacI family. The regulator genes are represented by black arrows. The adjacent genes are shown in white when they encode potential enzymes and in gray when they encode transporters. The transcription direction of the genes is given by the direction of the arrows. Both the ID number and the name of the gene are given below the arrows of the studied genes. The white flags indicate the uidA-kanamycin fusions in the structural genes and the black circles indicate the chloramphenicol insertions in the regulator genes. The name of the strain containing the mutation is given above these drawings.

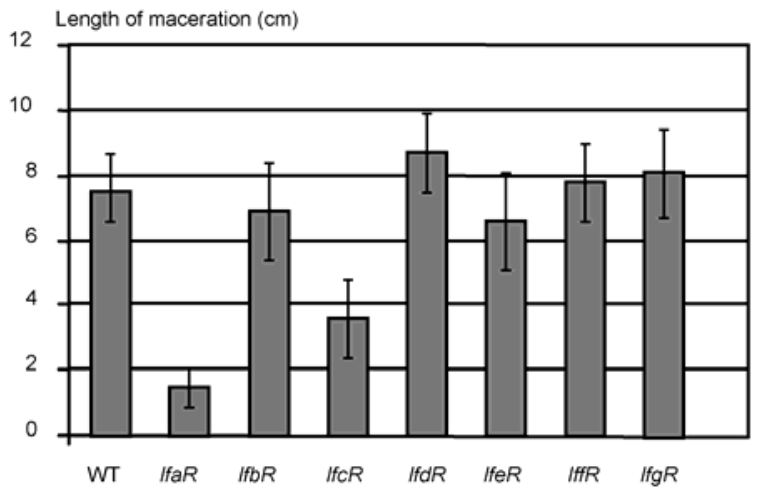

Fig. 2. Virulence of the regulator mutants on chicory leaves. After infection with each regulator mutant and the wild-type strain 3937 (WT), the leaves were incubated for $24 \mathrm{~h}$ and the length of rotted tissue was measured to estimate the disease severity. The mean value and the standard deviations reported correspond to 12 leaves inoculated with each strain. 
Each fusion was then transduced into the mutant containing a $\mathrm{Cm}^{\mathrm{r}}$ insertion in the corresponding regulator gene, using the phi-EC2 transducing phage. As expected for contiguous genes, a high frequency of cotransduction (50 to 90\%) was observed for each couple of mutations, and only kanamycin-resistant $\left(\mathrm{Km}^{\mathrm{r}}\right) \mathrm{Cm}^{\mathrm{r}}$ transductants were retained.

The expression of the fusions was then compared between strains containing, or not containing, the regulator mutation. The expression of $l f a A, l f c K$, lfeW, lffE, and $l f g N$ clearly increased in the regulator mutant, with factors of approximately 70-, 90-, 1,100-, 750-, and 120-fold, respectively (Table 3). Such high derepression demonstrates that LfaR, LfcR, LfeR,
LffR, and LfgR act as repressors to control the expression of $l f a A, l f c K, l f e W, l f f E$, and $l f g N$, respectively. In contrast, $l f b B$ and $l f d P$ expression was not affected by the inactivation of their adjacent regulator gene. LfbR and LfdR are either not involved in the control of these structural genes or the effect of the regulator mutation is not visible in our conditions.

Complementation tests were performed using plasmids containing the regulator genes $l f a R$, $l f c R$, lfeR, or $l f g R$ (Table $4)$. The plasmid encoding a given regulator was introduced in the strain bearing both the regulator inactivation and the fusion in the corresponding target gene (Table 3 ). The empty vector (pGEM-T) had no effect on the expression of the fu-
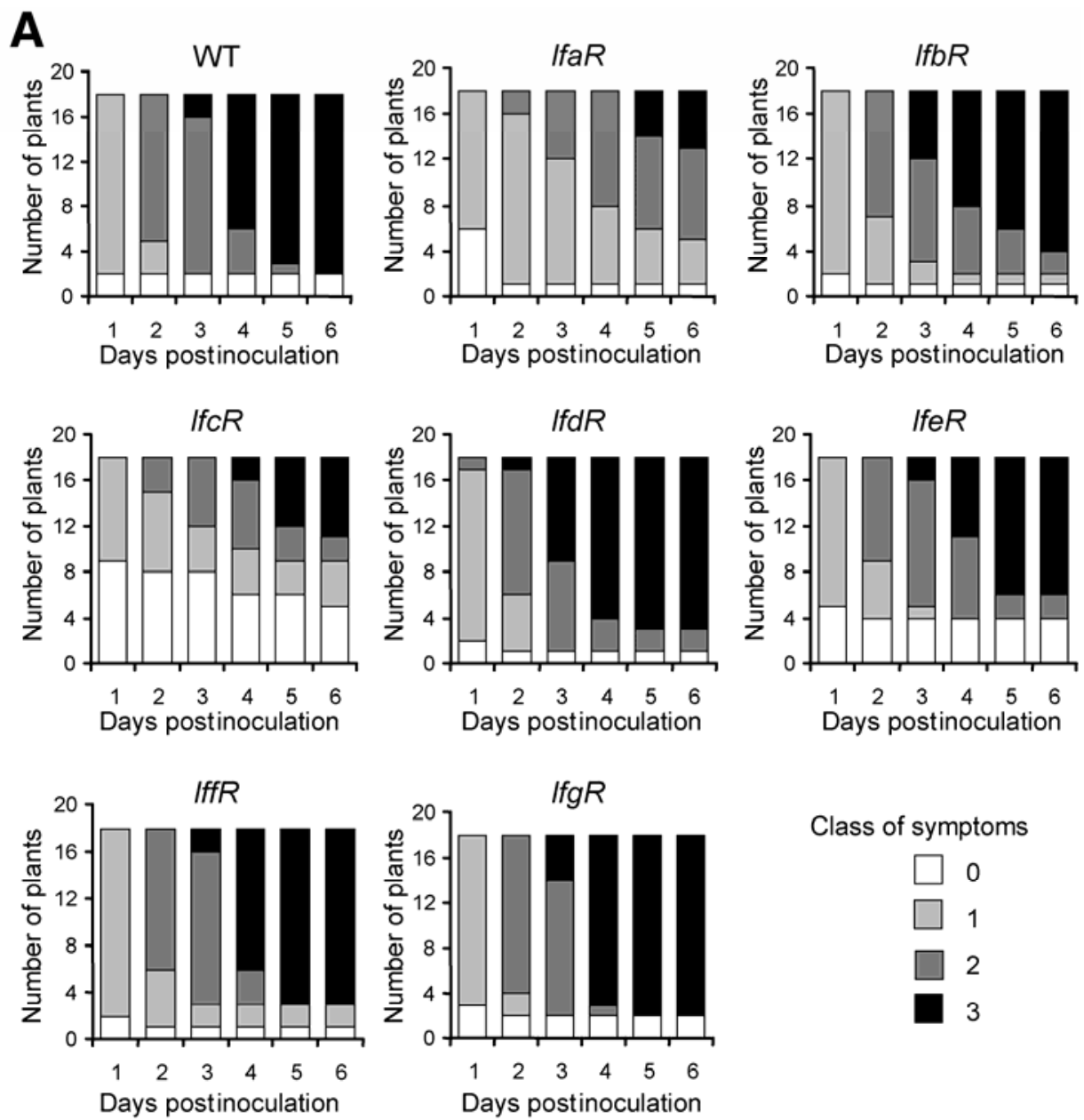

\section{Class of symptoms}
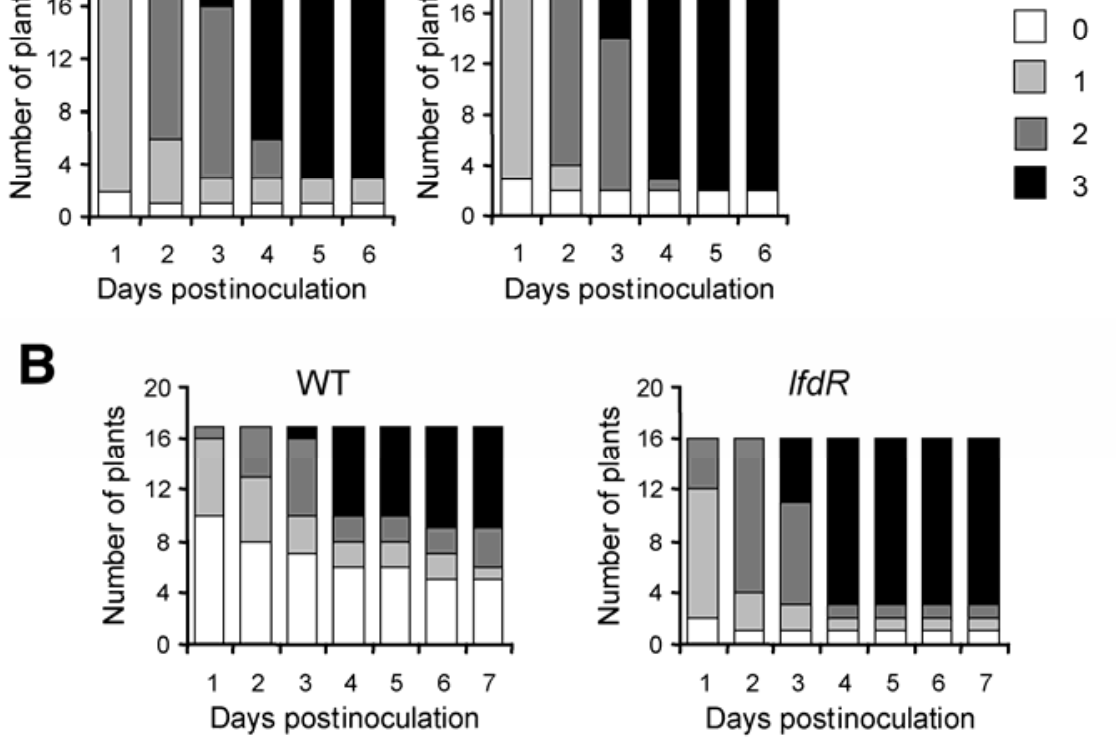

Fig. 3. Virulence of the regulator mutants in Saintpaulia ionantha. The evolution of the soft rot symptoms was followed after inoculation with the wild-type strain 3937 (WT) and the regulator mutants. A, Eighteen plants were inoculated by infiltration of a single leaf using a bacterial suspension at $10^{8}$ bacteria/ml. B, Similar inoculations were performed using a bacterial suspension at $10^{7}$ bacteria/ml. Symptom occurrence was scored daily for a week. Symptoms are classified in four stages as defined by Lebeau and associates (2008): stage 0, no symptoms; stage 1, rotting confined to the infiltrated zone; stage 2, maceration of the leaf limb; stage 3, maceration of the whole leaf including the petiole. In each column, the differently filled boxes correspond to the number of plants exhibiting a given stage of symptoms (identified as shown in the legend). At least three independent experiments were performed. In each case, the proportion of full symptomatic leaves was compared between the WT strain and mutant groups using the Fisher's exact test. Statistical significance was defined as $P=0.05$. The different experiments gave similar interpretations and results of a representative experiment are shown. 
sions (data not shown). Introduction of the regulator genes $l f a R$, lfcR, lfeR, and $l f g R$ affected the expression of the $l f a A$, $l f c K$, lfeW, and $l f g N$ fusions, respectively (Table 3). When compared with the same strain without plasmid, the high derepressed level of the $l f a A, l f c K$, lfe $W$, or $l f g N$ fusions decrease with factors of approximately 3-, 3-, 16-, and 2-fold, respectively. However, comparison with the strain bearing a wild-type allele of the regulator gene revealed only a partial complementation of the regulator mutation (Table 3 ). In the transformed strains, the expression of the fusion is intermediate between the level observed in the wild-type background and that in the regulator mutant (Table 3). With plasmid constructions, the intracellular concentration of the encoded regulator could differ from its concentration in the wild-type strain. Such variations could affect the expression of the target genes because the intracellular concentration of a repressor protein is often determinant in regulatory circuits (Nasser et al. 2001).

\section{In planta expression of the genetic fusions in the potential target genes.}

To determine whether the expression of the potential target genes is induced during plant infection, we followed the expression of the seven uidA fusions in planta. We first assayed the reporter enzyme in the macerated tissue following infection of chicory leaves. A fusion in the highly induced pectate lyase gene pelD (Hugouvieux-Cotte-Pattat et al. 1992) was used for comparison. After $24 \mathrm{~h}$ of infection of chicory leaves,
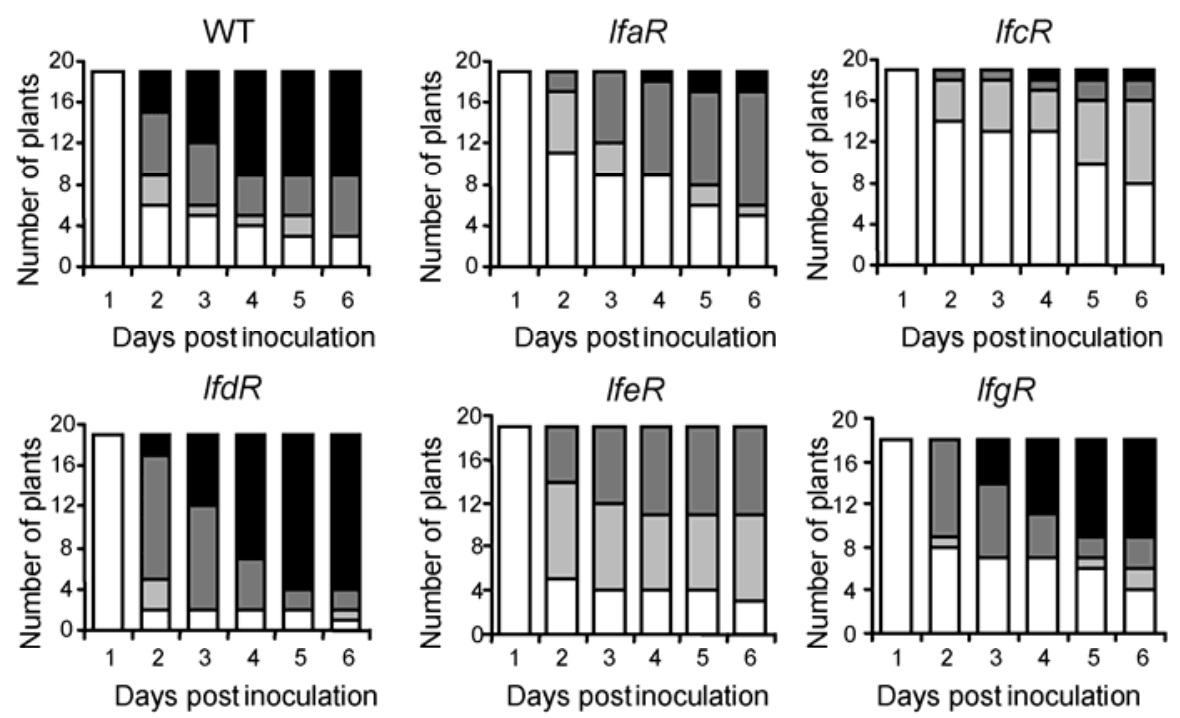

\section{Class of symptoms $\square 0 \quad \square 1 \quad \square 2 \quad \square 3$}

Fig. 4. Virulence of the regulator mutants in Arabidopsis thaliana. The evolution of the soft rot symptoms was followed after inoculation with the wild-type strain 3937 (WT) and the regulator mutants. Inoculation was performed by putting about 50 bacteria on a leaf wound. Symptom occurrence was scored daily for a week. Symptoms are classified in four stages as defined by Lebeau and associates (2008): stage 0, no symptom; stage 1, maceration of the area around the bacterial suspension droplet; stage 2, maceration extending to the other half of the leaf and along the central vein; stage 3 , total maceration of the leaf including the petiole. At least three independent experiments were performed. The proportion of full symptomatic leaves was compared between the WT strain and mutant groups using the Fisher's exact test. Statistical significance was defined as $P=0.05$. Results of a typical experiment are presented.

Table 3. Expression of transcriptional fusions and effect of regulator mutations and plant extract addition ${ }^{\mathrm{a}}$

\begin{tabular}{|c|c|c|c|c|}
\hline \multirow[b]{2}{*}{ Fusion } & \multirow[b]{2}{*}{ Regulator mutation } & \multirow[b]{2}{*}{ Plasmid } & \multicolumn{2}{|c|}{ Specific activity $\left(\mathrm{nmol} \mathrm{min}^{-1} \mathrm{mg}^{-1}\right)$ in } \\
\hline & & & Glycerol & Glycerol + plant extract \\
\hline lfaA::uidA & $\ldots$ & $\ldots$ & $7 \pm 3$ & $874 \pm 305$ \\
\hline lfaA::uidA & lfaR & $\ldots$ & $504 \pm 102$ & $395 \pm 96$ \\
\hline lfaA::uidA & lfaR & pI3366 lfaR $^{+}$ & $191 \pm 57$ & $433 \pm 131$ \\
\hline lfbB::uidA & $\ldots$ & $\ldots$ & $7 \pm 4$ & $10 \pm 3$ \\
\hline lfbB::vidA & $l f b R$ & $\ldots$ & $9 \pm 5$ & $\ldots$ \\
\hline lfcK::uidA & $\ldots$ & $\ldots$ & $212 \pm 68$ & $209 \pm 27$ \\
\hline lfcK::uidA & $l f c R$ & $\ldots$ & $18,823 \pm 1136$ & $\ldots$ \\
\hline lfcK::uidA & $l f_{c} R$ & $\mathrm{pI} 3133$, lfc $^{+}$ & $6,178 \pm 596$ & $\ldots$ \\
\hline lfdP::uidA & $\ldots$ & $\ldots$ & 0 & 0 \\
\hline lfdP::uidA & $l f d R$ & $\ldots$ & 0 & $\ldots$ \\
\hline lfeW::uidA & $\ldots$ & $\ldots$ & $4 \pm 3$ & $3 \pm 2$ \\
\hline lfeW::uidA & lfeR & $\ldots$ & $4,464 \pm 403$ & $\ldots$ \\
\hline lfeW::uidA & lfeR & $\mathrm{pI} 3156$, lfeR $^{+}$ & $272 \pm 80$ & $\ldots$ \\
\hline lffE::uidA & $\ldots$ & $\ldots$ & $12 \pm 5$ & $15 \pm 3$ \\
\hline lffE::uidA & lffR & $\ldots$ & $9,037 \pm 927$ & $\ldots$ \\
\hline lfgN::uidA & $\ldots$ & $\ldots$ & $13 \pm 4$ & $226 \pm 74$ \\
\hline lfgN::uidA & $\operatorname{lfg} R$ & $\ldots$ & $1,608 \pm 234$ & $1,796 \pm 269$ \\
\hline lfgN::uidA & lfgR & pI3367 lfgR ${ }^{+}$ & $971 \pm 272$ & $1,013 \pm 234$ \\
\hline
\end{tabular}

${ }^{a}$ Cells were grown at $30^{\circ} \mathrm{C}$ in minimal medium containing glycerol $\left(2 \mathrm{~g} \mathrm{liter}^{-1}\right)$, with or without the addition of a chicory leaf extract ( $1 \%$, vol/vol) as inducer. The results reported for $\beta$-glucuronidase activities are the mean value of at least three independent experiments and the corresponding standard deviations are indicated. 
the $\operatorname{lfgN}$ fusion was very highly expressed in the macerated tissue (Fig. 5A). The lfaA fusion was also expressed at a high level, similar to that observed for pelD. The lfcK and lffE fusions were expressed at low levels and no detectable expression of $l f b B$, lfdP, and $l f e W$ was observed.

To determine whether the expression of these genes varies according to the host plant, expression of the $l f a A, l f c K, l f d P$, lffE, and $l f g N$ fusions was also assayed in Arabidopsis. Although chicory leaf inoculations were classically performed at $30^{\circ} \mathrm{C}$, expression of the fusions in Arabidopsis was measured at $27^{\circ} \mathrm{C}$ and also at 19 and $24^{\circ} \mathrm{C}$, the usual condition for Arabidopsis pathogenicity tests (Fig. 5B). The fusion expression was measured in leaves exhibiting the initial stage of maceration (Fig. 4, stage 1). At both temperatures, the lfaA and $l f g N$ fusions were expressed at a level comparable with that observed for the pelD fusion while the $l c f K$ fusion was expressed at a low level and no detectable expression of $l f d P$ or lffE was observed.

Table 4. Erwinia chrysanthemi strains, plasmids, and oligonucleotides

\begin{tabular}{|c|c|c|c|}
\hline E. chrysanthemi & \multicolumn{2}{|c|}{ Genotype, description ${ }^{a}$} & Reference, origin \\
\hline \multicolumn{4}{|l|}{ Strains } \\
\hline 3937 & \multicolumn{2}{|l|}{ Wild-type strain } & Laboratory collection \\
\hline A4698 & \multicolumn{2}{|l|}{ lfaR::C $\mathrm{Cm}$} & This work \\
\hline A4391 & \multicolumn{2}{|l|}{ lfaA::uidA-Km } & This work \\
\hline A4797 & \multicolumn{2}{|l|}{ lfaR::Cm lfaA::uidA-Km } & This work \\
\hline A4593 & \multicolumn{2}{|l|}{$l f b R:: \mathrm{Cm}$} & This work \\
\hline A4657 & \multicolumn{2}{|l|}{ lfbB::uidA-Km } & This work \\
\hline A4792 & \multicolumn{2}{|l|}{ lfbR::Cm lfbB::uidA-Km } & This work \\
\hline A4595 & \multicolumn{2}{|l|}{ lfcR::Cm } & This work \\
\hline A4675 & \multicolumn{2}{|l|}{ lfcK::uidA-Km } & This work \\
\hline A4793 & \multicolumn{2}{|l|}{ lfcR::Cm lfcK::uidA-Km } & This work \\
\hline A4676 & \multicolumn{2}{|l|}{ lfdR::Cm } & This work \\
\hline A4654 & \multicolumn{2}{|l|}{ lfdP::uidA- Km } & This work \\
\hline A4789 & \multicolumn{2}{|l|}{ lfdR::Cm lfdP::uidA-Km } & This work \\
\hline A4646 & \multicolumn{2}{|l|}{ lfeR::Cm } & This work \\
\hline A4925 & \multicolumn{2}{|l|}{ lfeW::uidA-Km } & This work \\
\hline A4928 & lfeR::Cm lfeW::uidA-Km & & This work \\
\hline A4696 & lffR::Cm & & This work \\
\hline A4379 & lffE::uidA-Km & & This work \\
\hline A4790 & lffR::Cm lffE::uidA-Km & & This work \\
\hline A4662 & lfgR::Cm & & This work \\
\hline A4420 & lfgN::uidA-Km & & This work \\
\hline A4791 & lfgR::Cm lfgN::uidA-Km & & This work \\
\hline A 4415 & pelD::uidA-Km & & HCP $1992^{b}$ \\
\hline Plasmids & & & \\
\hline pGEM-T & Vector for direct cloning of polymerase chain re & $(\mathrm{PCR})$ product, $\mathrm{Ap}^{\mathrm{r}}$ & Promega \\
\hline pI3073 & pGEM-T derivative with a $0.95-\mathrm{kb}$ PCR fragme & & This work \\
\hline pI3366 & pGEM-T derivative with a $1.3-\mathrm{kb}$ PCR fragmen & & This work \\
\hline pI3031 & pGEM-T derivative with a $1.05-\mathrm{kb}$ PCR fragme & & This work \\
\hline pI3128 & pGEM-T derivative with a $1.1-\mathrm{kb}$ PCR fragmen & & This work \\
\hline $\mathrm{pI} 3173$ & pGEM-T derivative with a $1.1-\mathrm{kb}$ PCR fragmen & & This work \\
\hline pI3133 & pGEM-T derivative with a $1.15-\mathrm{kb}$ PCR fragme & & This work \\
\hline pI3176 & pGEM-T derivative with a $1.15-\mathrm{kb}$ PCR fragme & & This work \\
\hline pI3174 & pGEM-T derivative with a $1.15-\mathrm{kb}$ PCR fragme & & This work \\
\hline pI3171 & pGEM-T derivative with a $1.05-\mathrm{kb}$ PCR fragme & & This work \\
\hline $\mathrm{pI} 3156$ & pGEM-T derivative with a $1.2-\mathrm{kb}$ PCR fragmen & & This work \\
\hline $\mathrm{pI} 3276$ & pGEM-T derivative with a $1.15-\mathrm{kb}$ PCR fragme & & This work \\
\hline $\mathrm{pI} 3071$ & pGEM-T derivative with a $1.15-\mathrm{kb}$ PCR fragme & & This work \\
\hline pI3024 & pGEM-T derivative with a $1.05-\mathrm{kb}$ PCR fragme & & This work \\
\hline pI3175 & pGEM-T derivative with a $1-\mathrm{kb}$ PCR fragment, & & This work \\
\hline pI3367 & pGEM-T derivative with a $1.3-\mathrm{kb}$ PCR fragmen & & This work \\
\hline pI2862 & pGEM-T derivative with a $1.2-\mathrm{kb}$ PCR fragmen & & This work \\
\hline Oligonucleotides $^{c}$ & & & \\
\hline lfaR & GCGGATCCTCAAAATTCGTGAAATCGC & GCTCTAGATCAGCTGAAGCTGTAACAAC & $\ldots$ \\
\hline lfaR 2 & GC $\overline{\text { GGATCC }}$ GCCTTTTTCTGGTGATG & GCTCTAGACTCAGGCATCATATAAATCGG & $\ldots$ \\
\hline lfaA & GC $\overline{\text { GGATCC }}$ ATTGAAACATTGGGTATTGC & GCTCTAGATCCTGTAACAGGCAGG & $\ldots$ \\
\hline lfbR & GCGGATCCTGGCTGTTCAGCCTG & GCTCTAGATAAGCTTGAACGCAATC & $\ldots$ \\
\hline lfbB & GCGGATCCGGCGTACAGTTGATGG & GCTCTAGACCACTTTGGATTTGGCG & $\ldots$ \\
\hline lfcR & 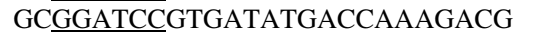 & 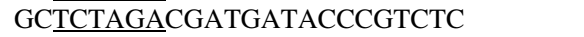 & $\ldots$ \\
\hline lfcK & 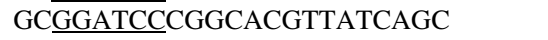 & GC $\overline{\text { TCTAGA }}$ CGGCTCATCTGTTGCTG & $\ldots$ \\
\hline lfdR & GCGGATCCACAGTATCACGGGTGTTG & GCTCTAGATTATCTGGTGTTCCATGACACC & $\ldots$ \\
\hline lfdP & CGCCAAGATCTCCTTCGGCC & GCTCTAGATTCTTGTGGTGGTTCCAC & $\ldots$ \\
\hline lfeR & GCGGATCCACGAAACGGACGCC & GCTCTAGATGCACATCAGCCAGCG & $\ldots$ \\
\hline lfeW & 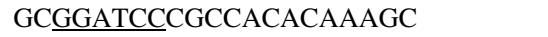 & GCTCTAGAGCGACGTTCTTCAGC & $\ldots$ \\
\hline lffR & GCGGATCCCTGCGACTTCG & GCTCTAGAAGACTGTCAGGGTCATTG & $\ldots$ \\
\hline lffE & GCGGATCCAAACAATAAAAGGGCC & GCTCTAGACGCGTTTTCTCCTTTCAG & $\ldots$ \\
\hline lfgR & 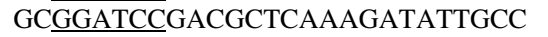 & 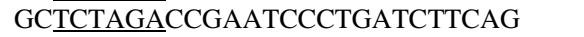 & $\ldots$ \\
\hline lfgR $R_{2}$ & GCGGATCCACCGGCATTGCCAACAC & GC $\underline{T C T A G A T G G A A A C G T T A G C A A G C G C ~}$ & $\ldots$ \\
\hline $\operatorname{lfgN}$ & GCGGATCCGACACGGTGTCGGTAATAC & GCTCTAGATGTTTTCAAACCCGTTTCTG & $\ldots$ \\
\hline
\end{tabular}

${ }^{\mathrm{a}} \mathrm{Km}=$ kanamycin, $\mathrm{Cm}=$ chloramphenicol, and $\mathrm{Ap}^{\mathrm{r}}=$ ampicillin resistant.

${ }^{\mathrm{b}} \mathrm{HCP}=$ Hugouvieux-Cotte-Pattat and associates (1992).

${ }^{\mathrm{c}}$ Restriction sites are underlined. 
Effect of plant extracts on the expression of the genetic fusions in the potential target genes.

To determine whether the expression of the transcriptional fusions is induced by a plant component, we assayed the fusions in various culture media. The expression of each fusion in the potential target genes was analyzed in glycerol minimal medium supplemented, or not, with $1 \%$ chicory leaf extract (Table 3). No expression of the $l f d P$ fusion was detected in both media. In glycerol minimal medium, fusions in lfaA, $l f b B, l f f E$, and $l f g N$ were expressed at a low basal level whereas the $l f c K$ fusion was more highly expressed than the other. Addition of the plant extract did not modify the expression of $l f b B, l f c K$, lfdP, lfe $W$, and $l f f E$. In contrast, both the $l f a A$ and $l f g N$ fusions were clearly induced in the presence of the extract, with induction ratios of 125 and 17 , respectively. The level of $l f a A$ expression in the presence of the plant extract nearly reached the derepressed level observed in the lfaR mutant (Table 3). The expression of the $l f g N$ fusion after addition of the plant extract remained lower than that reached in the lfgR mutant (Table 3), indicating that this extract provokes only a partial induction of $l f g N$.
Various sugars or plant compounds were then tested for a potential effect on the expression of the $l f a A$ and $l f g N$ fusions. None of the following compounds showed an inducing effect: arabinogalactan, L-arabinose, arbutine, cellobiose, D-fructose, L-fucose, D-galactose, D-galacturonate, D-glucose, D-glucuronate, D-mannose, pectin, polygalacturonate, L-rhamnose, rhamnogalacturonan, salicine, sucrose, or D-xylose. Thus, the inducer or inducers of the $l f a A$ and $l f g N$ genes remain to be determined.

\section{DISCUSSION}

Among the 18 regulators of the LacI family encoded by the E. chrysanthemi 3937 genome, 7 regulators are involved in totally unknown pathways. They were designated as LfaR, LfbR, LfcR, LfdR, LfeR, LffR, and LfgR. Homologous proteins are encoded by other bacterial genomes but no function has been assigned to them. The five regulators LfaR, LfdR, LfeR, LffR, and LfgR are conserved in the closely related pectinolytic species, E. carotovora (67 to $78 \%$ identity) (Table 1). LfbR homologs are encoded only by plant-associated bacterial genera, such as Rhizobium and Agrobacterium. LfcR homologs are
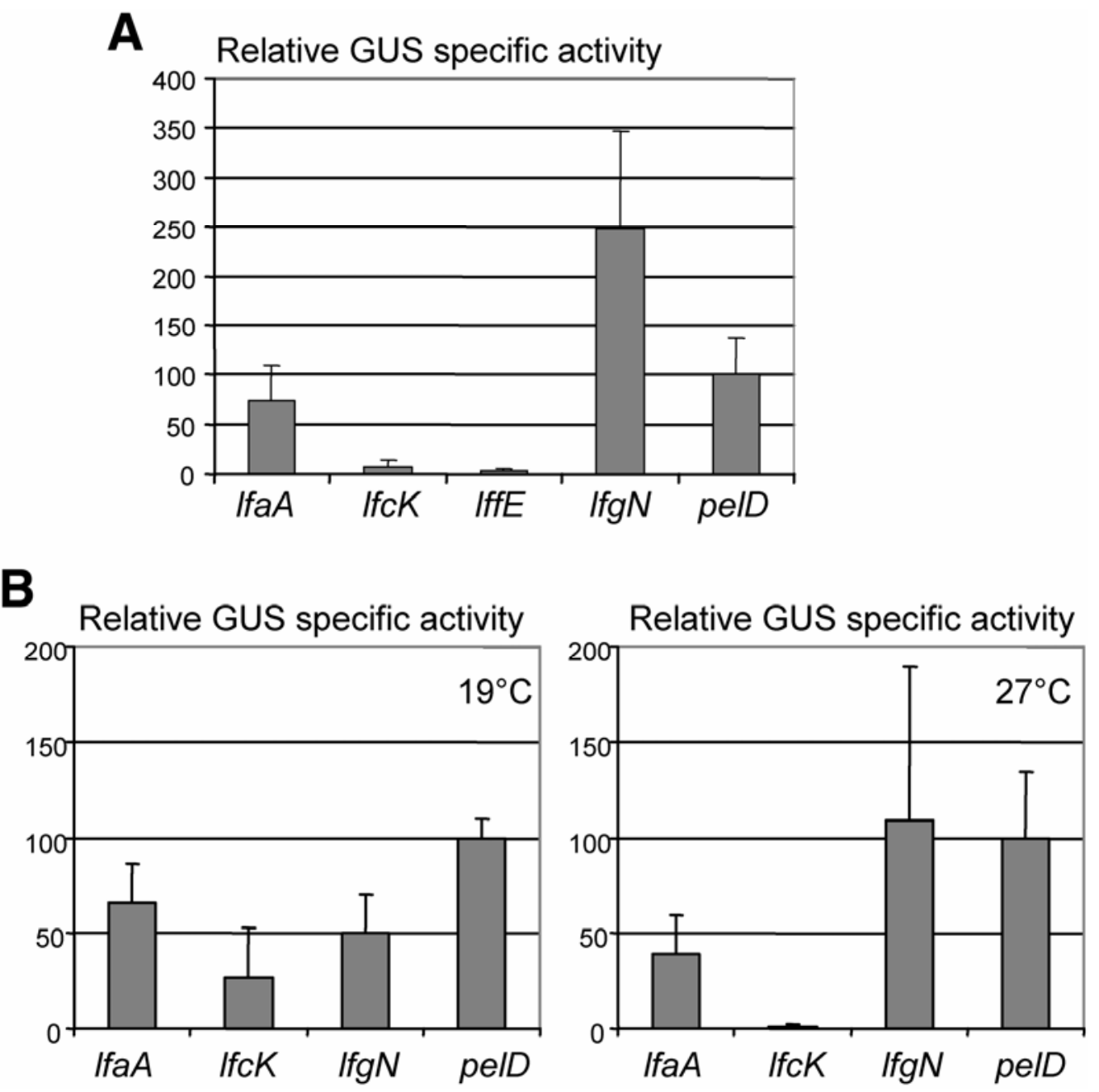

Fig. 5. Expression of the structural genes during plant infection. A, Chicory leaves or B, Arabidopsis plants were infected with strains containing a uidA fusion. A fusion in the pelD gene was used as the positive control in each experiment and $\beta$-glucuronidase (GUS) activities are expressed as a percentage of the pelD fusion. After incubation for $\mathbf{A}, 24 \mathrm{~h}$ at $30^{\circ} \mathrm{C}$ or $\mathbf{B}, 24 \mathrm{~h}$ at $27^{\circ} \mathrm{C}$ or $48 \mathrm{~h}$ at alternating temperatures of 19 and $24^{\circ} \mathrm{C}$ during night $(16 \mathrm{~h})$ and day $(8 \mathrm{~h})$ conditions, respectively, the macerated tissue was recovered to perform bacterial cell numeration and a GUS assay with either A, $p$-nitrophenyl- $\beta$-Dglucuronide or B, 4-methylumbelliferyl- $\beta$-D-glucuronide as substrate (see experimental procedures). To facilitate comparison between the different experiments and assay methods, GUS activities were expressed as a percentage of the pelD fusion, chosen as reference. The results of the specific activity reported are the mean value of $\mathbf{A}, 12$ leaves for chicory leaves and $\mathbf{B}$, four plants for Arabidopsis, and the corresponding standard deviations are indicated. No data are reported for the $l f b B$, lfdP, and $l f e W$ fusions because no GUS activity could be detected after infection with these strains. Similarly, no GUS activity was detected when the wild-type strain was used as negative control. 
found in distant bacterial genera, such as Chromobacterium and Vibrio. The genetic environment of each regulator was examined to detect conserved adjacent genes that could constitute functional units. The seven regulators of the LacI family are clustered with genes encoding putative enzymes and transport systems of different families, either the major facilitator superfamily (MFS), the ATP binding cassette (ABC) family, or the phosphoenolpyruvate-dependent phosphotransferase system (PTS) family (Fig. 1; Table 2). In some cases, homologies have been detected for the potentially encoded enzymes. However, the identity scores are insufficient to predict the function of the selected regions. To gain information on these regulators, we inactivated the corresponding genes and we constructed transcriptional fusions in potentially controlled adjacent genes. Then, we analyzed the behavior of each regulator mutant and fusion after plant infection.

Locus lfa. The pathogenicity of the lfaR mutant is affected on the different plants tested, with a decreased maceration on chicory leaves and an attenuated virulence on whole plants (Figs. 2 through 4). The gene lfaR is adjacent to two genes, lfaT and lfaA, which are probably cotranscribed (Fig. 1). This cluster of three genes is conserved, with the same genetic organization, in the genome of other pathogenic enterobacteria, E. carotovora, Yersinia pestis, Y. pseudotuberculosis, Shigella sonnei, and in some Escherichia coli strains (Table 1). The gene lfaT encodes an MFS permease. The gene lfaA encodes a member of the glycosylhydrolase family 31 (Coutinho et al. 2003). In addition to proteins of undetermined function, this family includes $\alpha$-glucosidases, glucoamylases, sucrase-isomaltases, $\alpha$-xylosidases, $\alpha$ glucan lyases, and isomaltosyltransferases. Thus, enzymes of the family GH31 cleave different $\alpha$-glycosidic linkages (1-1, 1-2, 1$3,1-4$, and 1-6) in various substrates. We observed that the gene IfaA is highly expressed during plant infection and is specifically induced by a plant component (Table 3 ). LfaR acts as a repressor of $l f a A$ expression and probably responds to an inducer of plant origin. These preliminary data suggest that the lfa locus is involved in the degradation of a plant component containing an $\alpha$-glucosidic bond, such as a glycoside or an oligosaccharide. The decreased virulence of the lfaR mutant suggests a role of the lfa substrate in the plant-bacteria interaction. Recently, deletion of a homologous cluster (aec-35-36-37) included in a genomic island of an extraintestinal avian-pathogenic E. coli strain was shown to attenuate the virulence for chickens (Chouikha et al. 2006). The conservation of this locus in pathogenic enterobacteria and its involvement in the virulence of an animal pathogen suggest that the lfa substrate is a general signal involved in the interaction between pathogenic enterobacteria and their eukaryotic hosts. The characterization of the lfa substrate would be very useful in acquiring information about this locus and in understanding its role in pathogeny.

Locus lfb. LfbR is not involved in the virulence of Erwinia chrysanthemi on all the tested plants. The best identity score of LfbR was found with a Rhizobium protein (Table 1). An LfbR homolog is also encoded by E. carotovora but the low identity score suggests that this homolog is not an LfbR ortholog. Five genes are clustered with $l f b R$ on the E. chrysanthemi chromosome. They encode a putative enzyme $(\mathrm{LfbE})$ and the four elements of an $\mathrm{ABC}$ transporter, including the periplasmic binding protein LfbB (Table 2; Fig. 1). The genes lfb seem to be organized in a large operon, with the last gene encoding the regulator. This type of organization appears to be quite frequent because it is also observed for the lfc, lff, and lfg loci (Fig. 1). The gene $l f b B$ is not expressed in planta and LfbR has no repressor effect on $l f b B$ expression. Similar results were obtained by analysis of a transcriptional fusion in $l f b E$ (data not shown). Thus, LfbR is either a positive regulator of the $l f b$ operon or it is not involved in its transcription. Positive regulators are not frequent in the LacI family but some cases have been experimentally demonstrated (Bausch et al. 1998).

Locus lfc. The virulence of the $l f c R$ mutant is strongly affected on whole plants and, to a lesser extent, on chicory leaves (Figs. 2 through 4). LfcR homologs are present in only a few bacteria, including Chromobacterium and Vibrio spp. (Table 1). LfcR shares $31 \%$ identity with the regulator ScrR involved in sucrose catabolism but a true ScrR ortholog is encoded by the $E$. chrysanthemi genome (Table 1). The four genes clustered with $l f c R$ encode an MFS transporter, two hypothetical proteins, and a putative sugar kinase, LfcK (Table 2; Fig. 1). We show here that LfcR is a repressor of $l f c K$ expression (Table 3). The $l f c K$ gene is quite highly expressed in liquid cultures (Table 3 ). Its expression is not induced in the presence of sucrose (data not shown). However, the $l f c K$ gene appeared to be moderately expressed in planta. Complementary analysis of the phenotype of the $l f c R$ mutant revealed a decreased production of the extracellular enzymes, pectinases, cellulases, and proteases compared with the wild-type strain (data not shown). Thus, LfcR positively controls the genes encoding these enzymes. This positive regulation could be either direct or indirect; for instance, resulting from a cascade of regulation or from the modification of the physiological state in the mutant. To understand the LfcR effect better, it would be interesting to perform a transcriptome analysis of the $l f c R$ mutant to identify the other direct or indirect targets of the regulator. In any case, the reduced virulence of the $l f c R$ mutant could be explained by the decreased production of extracellular plant cell-wall-degrading enzymes, which are the main $E$. chrysanthemi factors causing maceration.

Locus lfd. The lfdR mutant was more efficient than the wildtype strain in initiating maceration on whole plants (Fig. 3). LfdR shares $46 \%$ identity with the Escherichia coli AscG regulator whose function has not been clearly characterized. LfdR homologs are also found in Erwinia carotovora and Salmonella spp. (Table 1). The gene $l f d R$ is situated in the vicinity of three genes encoding the components of the sugar-specific enzyme II of a PTS transporter (Table 2; Fig. 1) and of the gene $l f d P$, which encodes a member of the glycoside hydrolases family 1 (Coutinho et al. 2003). Considering its homologs, $\mathrm{LfdP}$ is predicted to be a 6 -phospho- $\beta$-glucosidase. The gene $l f d P$ is not expressed either in vitro or in planta and no regulation of $l f d P$ by $L f d R$ could be detected. Thus, LfdR probably regulates other targets. Contrary to the other LacI family regulators involved in pathogenicity, the inactivation of $l f d R$ appears to favor the initiation of infection (Fig. 3). Such a phenotype was previously observed for a pecS mutant (Reverchon et al. 2002). PecS is a global regulator that represses the expression of several virulence factors necessary in the first steps of infection. Because the pecS mutation accelerates pectate lyase production, the initiation of maceration is facilitated. LfdR does not affect pectate lyase production (data not shown) but it could control the production of other virulence factors. A transcriptome analysis of the $l f d R$ mutant could reveal potential LfdR targets involved in the early steps of pathogeny.

Locus lfe. The lfeR mutant showed a reduced virulence on Arabidopsis (Fig. 4). Homologs of LfeR are detected in various bacteria, mostly found in soil or associated with plants, including E. carotovora, Ralstonia spp., and Streptomyces spp. (Table $1)$. Only one gene is grouped with lfeR on the E. chrysanthemi chromosome and it encodes a putative enzyme, LfeW (Table 2; Fig. 1). LfeR acts as a repressor of lfeW expression and the lfeW gene is weakly expressed in planta. In the absence of additional data, it is not clear why the derepression of $l f e W$ would provoke the reduced virulence of the lfeR mutant.

Locus lff. LffR is not involved in E. chrysanthemi virulence. A homolog of LffR is found in E. carotovora and also in various bacteria which are not associated with plants, such as Mann- 
heimia, Thermoanaerobacter, and Bacillus spp. (Table 1). Five genes are clustered with lffR on the E. chrysanthemi chromosome (Table 2; Fig. 1). They encode a hypothetical protein, an MFS transporter, and three putative enzymes, including a protein, LffE, sharing $27 \%$ identity with IolE, an enzyme involved in myo-inositol catabolism (Yoshida et al. 2004). LffR is a repressor of $l f f E$ expression. The lffE gene is moderately expressed in planta. We verified that lffe expression is not induced in the presence of myo-inositol (data not shown). Thus, the lff locus is probably involved in the degradation of a compound present in the environment that could be related to inositol.

Locus lfg. Despite the fact that LfgR homologs are encoded only by the plant-associated bacteria E. carotovora, Rhizobium spp., and Agrobacterium spp. (Table 1), the virulence of the lfgR mutant is not affected in the tested conditions. The five genes clustered with lffR (Fig. 1) encode the four elements of an $\mathrm{ABC}$ transporter and a putative enzyme, LfgN, sharing $44 \%$ identity with RhiN, which is involved in rhamnogalacturonan catabolism (Hugouvieux-Cotte-Pattat 2004). The role of RhiN is to cleave, by an unknown mechanism, the small oligomers generated by a rhamnogalacturonan lyase. The gene $\lg \mathrm{N}$ is highly expressed in planta and is specifically induced by a plant component (Table 2). LfgR acts as a repressor on $l f g N$ expression and could respond to the plant inducer. Because the rhiN expression is induced in the presence of galacturonate and rhamnose, we tested the effect of these compounds on lfgN. Neither galacturonate, polygalacturonate, rhamnose, nor rhamnogalacturonan induced the $l f g N$ expression. Thus, the $l f g$ locus is probably involved in the degradation of another type of plant cell wall oligosaccharide.

In summary, analysis of transcriptional fusions demonstrated that five regulators of the LacI family, LfaR, LfcR, LfeR, LffR, and LfgR, act as the repressors of an adjacent gene. The regulators of the LacI family are often repressors of the transcription of the controlled genes. Among the 14 LacI regulators of Escherichia coli $\mathrm{K}-12$, there is one case of positive regulation (IdnR) (Bausch et al. 1998) and one case of dual control because FruR could act as either a positive or negative regulator, depending on the target (Ramseier et al. 1995). The inactivation of a repressor leads to a derepression of the controlled genes that can be easily detected. In contrast, to observe the effect of activator inactivation it is necessary to know the conditions in which the controlled gene is expressed. Thus, an absence of any effect of the regulator mutation does not always mean an absence of control. The data obtained with LfbR and LfdR result from either an absence of control of the tested adjacent genes or a positive regulation not detectable in our conditions. However, no expression of the $l f b$ and $l f d$ fusions could be detected in planta, indicating that, even if they are positively regulated, no activation of these genes occurs in the macerated tissue.

Among the five genes controlled by the adjacent repressors, four are expressed during plant infection. Most often the expression of a locus is linked to its involvement in pathogeny. This is clear for the gene $l f a$, which is highly expressed during infection, and also for the genes $l f c$ and $l f e$, which are expressed in planta. The gene $l f g$ is the only example in our study for which a high expression in planta is not associated with an effect on virulence. This suggests that the locus $l f g$ has an accessory role during plant infection or that it has a role in other untested host plants. Further analysis of the fusions demonstrated that two of them are specifically induced by the addition to the culture medium of a crude plant extract, corresponding to a plant juice. The plant extracts probably induce the genes $l f a$ and $l f g$ by derepression of the LacI-family regulators $\mathrm{LfaR}$ and $\mathrm{LfgR}$, respectively. The next challenge, of course, will be to identify the inducers of the $l f a$ and $l f g$ loci.
A few regulators of the LacI family have already been shown to be involved in bacterial virulence against animals. PtxS, a LacI family regulator of $P$. aeruginosa, is a negative regulator of the $k g u$ operon involved in 2-ketogluconate utilization (Swanson et al. 2000) but it is also involved in the activation cascade of exotoxin A by a poorly understood mechanism (Colmer and Hamood 1998). In Streptococcus pneumoniae, two LacI family regulators are involved in the adaptive response to the host. Both $\operatorname{RegM}$ and $\operatorname{RegR}$ have a dual function. RegM is a repressor of some enzymes but it activates biosynthesis of the capsular polysaccharide. RegR modulates virulence by repression of hyaluronidase and activation of adherence to animal cells (Chapuy-Regaud et al. 2003). Interestingly, as was observed in our study for three Erwinia chrysanthemi regulators of the LacI family, the virulence of the ptx $S$, regM, and regR mutants is attenuated (Colmer and Hamood 1998; Giammarinaro and Paton 2002).

Most known regulators of the LacI family are involved in degradation pathways (Table 1). Catabolic pathways could be necessary for the assimilation of carbon sources during the saprophytic life of the bacteria. During the infection process, they can be important for the use of main or secondary carbon sources when bacterial multiplication is rapid. No difference was observed between the wild-type strain and the mutants constructed in this study for their growth in rich or minimal media complemented with either sugars or plant extracts (data not shown). Alternatively, degradative enzymes can serve to eliminate toxic compounds or plant elicitors, thus increasing the bacterial fitness or altering the plant resistance. Notably, three mutants inactivated for a repressor of the LacI family (LfaR, LfcR, and LfeR) showed a reduced virulence, provoking attenuated symptoms or a delay in their appearance. This indicates that the correct production of virulence factors is influenced either directly or indirectly by these regulators. The lfaR mutant also showed an alteration in bacterial growth during the first steps of infection, suggesting that it is affected for early adaptation to the plant environment. Because a range of virulence factors has been characterized in E. chrysanthemi, we evaluated the impact of the regulator mutations on extracellular enzymes, exopolysaccharide, and indigoidine. The sole difference was a decrease of pectate lyase, cellulase, and protease production in the $l c f R$ mutant (data not shown). Thus, inactivation of LcfR suggested a positive regulatory effect on the production of extracellular degrading enzymes. It would be interesting to analyze whether LcfR directly acts on these virulence genes or whether perturbations in the regulation of the Lcf-related pathway could indirectly affect virulence.

In conclusion, the analysis of regulators of the LacI family allows identification of four additional regulators which are important for $E$. chrysanthemi virulence, namely LfaR, LfcR, $\mathrm{LfdR}$, and LfeR. The inactivation of $l f d R$ favors the initiation of soft rot, as observed for other negative regulators. In contrast, the inactivation of LfaR, LfcR, and LfeR results in a delayed or decreased virulence. These three regulators negatively control genes involved in the transport and catabolism of unknown substrates. The derepression of these putative catabolic pathways results in an attenuated virulence, suggesting that subtle metabolic changes could alter the proper production of bacterial factors leading to a successful infection.

\section{MATERIALS AND METHODS}

\section{Strains, media, and growth conditions.}

The bacterial strains of E. chrysanthemi and the plasmids used in this study are listed in Table 4. The phage Phi-EC2 was used to transfer the uidA-Km fusions in the regulator mutants by generalized transduction (Resibois et al. 1984). E. chrysan- 
themi cells were grown at $30^{\circ} \mathrm{C}$ in minimal medium M63 or Luria-Bertani (LB) rich medium (Miller 1972). Carbon sources were added to minimal medium at $2 \mathrm{~g} \mathrm{liter}^{-1}$. The plant extract, a crude juice obtained from chicory leaves and sterilized by filtration through $0.45 \mu$, was used at the final concentration of $1 \%(\mathrm{vol} / \mathrm{vol})$. The media were solidified with agar $\left(15 \mathrm{~g} \mathrm{liter}^{-1}\right)$. When required, antibiotics were added at the following concentrations: $\mathrm{Km}, 20 \mu \mathrm{g} \mathrm{ml}^{-1}$; ampicillin (Ap), $50 \mu \mathrm{g}$ $\mathrm{ml}^{-1}$; or $\mathrm{Cm}, 20 \mu \mathrm{g} \mathrm{ml}^{-1}$.

\section{Recombinant DNA techniques.}

Preparation of plasmid or chromosomal DNA, restriction digestions, ligations, DNA electrophoresis, and transformations were carried out as previously described (Sambrook et al. 1989). Sequence data were obtained from the genome sequencing project for the E. chrysanthemi strain 3937.

Polymerase chain reaction (PCR) primers (19 to 30 mers) were designed to amplify approximately $1 \mathrm{~kb}$ of $E$. chrysanthemi 3937 chromosomal DNA overlapping the selected gene (Table 4). Restriction sites were added to each primer to facilitate determination of the DNA orientation in the vector (BamHI or BglII at the $5^{\prime}$ end and XbaI at the $3^{\prime}$ end). The PCR products were purified (QIAquick PCR purification kit, Qiagen), and ligated to the pGEM-T vector (Promega) which has a protruding $\mathrm{T}$ nucleotide at each $3^{\prime}$ end. To construct nonpolar insertions, each regulator gene was inactivated by insertion of the CKC15 $\mathrm{Cm}^{\mathrm{r}}$ cassette (Lebeau et al. 2008) into a restriction site situated inside the corresponding open reading frame. The following sites were used: HincII for lfaR and $l f d R$, $E h e \mathrm{I}$ for $l f b R, S a l \mathrm{I}$ for $l f c R$ and $l f f R, E c o \mathrm{RV}$ for $l f e R$, and $S a c \mathrm{II}$ for $l f g R$.

Genetic fusions were constructed on selected structural genes by insertion of uidA-Km cassettes (Bardonnet and Blanco 1992) into a restriction site situated inside the corresponding open reading frame. The following sites were used: EcoRI for $l f a A$ and $l f b B$, HincII for $l f c K, M a m$ I for $l f d P$, SacII for $l f e W$ and $l f g N$, and Eco47III for lffE. The orientation of the uidA-Km cassette was determined by restriction analysis. Only plasmids in which uidA and the mutated gene have the same transcriptional direction were retained.

Plasmids bearing the $\mathrm{Cm}^{\mathrm{r}}$ or $u i d A-\mathrm{Km}^{\mathrm{r}}$ insertions were then introduced into E. chrysanthemi cells by electroporation. The insertions were integrated into the E. chrysanthemi chromosome by marker exchange recombination after successive cultures in low-phosphate medium, in the presence of the appropriate antibiotic (Roeder and Collmer 1985). Verification of the correct recombination of the insertions was performed by PCR using the primers designed for cloning the corresponding gene (Table 4).

\section{Pathogenicity tests.}

Chicory leaves were inoculated as previously described (Hugouvieux-Cotte-Pattat 2004). Prior to infection, leaves were slightly wounded in their center to define the inoculation site. Twelve leaves were infected for each strain using $10^{6}$ bacteria $\left(10 \mu \mathrm{l}\right.$ of a suspension at $10^{8}$ bacteria/ml $)$. After incubation in a dew chamber for $24 \mathrm{~h}$ at $30^{\circ} \mathrm{C}$, the length of rotted tissue was measured to estimate the disease severity.

Saintpaulia and Arabidopsis plants were inoculated as described by Lebeau and associates (2008). Briefly, 1-month-old Saintpaulia cuttings were inoculated by wounding the lower part of the leaf followed by infiltration of a bacterial suspension at $10^{8}$ or $10^{7}$ bacteria/ml in $100 \mathrm{mM} \mathrm{KCl}$ with a $1-\mathrm{ml}$ syringe without a needle; 6-week-old Arabidopsis plants were inoculated by wounding the leaf with a needle and then depositing a 5- $\mu$ l drop of $\mathrm{KPO}_{4}$ buffer $(50 \mathrm{mM}, \mathrm{pH}$ 7) containing 50 bacteria. The plants were incubated at saturated humidity and in short-day conditions ( $8 \mathrm{~h}$ of light). For virulence analysis, symptoms were scored daily for a week. For assay of the gene fusions, the macerated tissue was recovered at 24 or $48 \mathrm{~h}$ after incubation at either $27^{\circ} \mathrm{C}$ or alternating temperatures of 19 and $24^{\circ} \mathrm{C}$ during night $(16 \mathrm{~h})$ and day $(8 \mathrm{~h})$ conditions, respectively.

\section{Enzyme assays.}

$\beta$-Glucuronidase activity was measured to estimate the expression of the fused genes (Bardonnet and Blanco 1992). Samples were taken at the end of the exponential growth phase and toluene was added to disrupt the cells. The degradation of $p$-nitrophenyl- $\beta$-D-glucuronide into $p$-nitrophenol was followed at $405 \mathrm{~nm}$. Specific activity is expressed as nmol of product liberated per minute per milligram of bacterial dry weight.

\section{Expression of fusions in planta.}

For chicory leaves, the plant macerated tissue was recovered after infection and used to perform bacterial cell numeration and $\beta$-glucuronidase assay. The number of colony-forming bacteria was determined by serial dilutions on LB plates containing kanamycin. The results of enzyme assays were normalized to account for the number of bacteria present in each sample. The $\beta$-glucuronidase-specific activity was calculated in nmol of product formed per $10^{9}$ bacteria. This specific activity is representative of the level of fusion expression in the macerated tissue. For expression in chicory leaves, after $24 \mathrm{~h}$ of infection at $30^{\circ} \mathrm{C}$, macerated tissue was recovered and mixed with the same volume of $\mathrm{KPO}_{4}$ buffer, $100 \mathrm{mM}, \mathrm{pH}$ 7. $\beta$-Glucuronidase assay was performed by following the degradation of $1 \mathrm{mM} p$-nitrophenyl- $\beta$-D-glucuronide in the same buffer, using $50 \mu \mathrm{l}$ of samples in a 1-ml final reaction mixture. For expression in Arabidopsis, 6-week-old plants were inoculated, as described above, and incubated at either 27 or 19 and $24^{\circ} \mathrm{C}$ for 24 or $48 \mathrm{~h}$, respectively. Leaves exhibiting the initial stages of maceration (stage 1) were collected and crushed in $40 \mu \mathrm{l}$ of $\mathrm{KPO}_{4}$ buffer ( $\left.50 \mathrm{mM}, \mathrm{pH} 7\right)$. These samples were used to perform bacterial cell numeration and $\beta$-glucuronidase assays using a protocol adapted from that described by Jefferson and associates (1987). Samples (10 $\mu \mathrm{l}$ each) were incubated with 1 $\mathrm{mM}$ 4-methylumbelliferyl- $\beta$-D-glucuronide in a $200-\mu \mathrm{l}$ final reaction mixture. Fluorescence was measured with excitation at $360 \mathrm{~nm}$ and emission at $460 \mathrm{~nm}$ at 1-min intervals for 60 min using a CytoFluor 4000 multiwell plate reader fluorimeter (PerSeptive Biosystems, Framingham, MA, U.S.A.). For the different plants, the wild-type strain used as negative control gave no detectable $\beta$-glucuronidase activity. A fusion in the pelD gene was used as the positive control in each experiment (Masclaux et al. 1996). To facilitate comparison between the different experiments and assay methods, $\beta$-glucuronidase activities were expressed as a percentage of the pelD fusion, chosen as reference.

\section{In planta bacterial growth.}

Six to eight Arabidopsis leaves were infected after wounding by deposit of a bacterial suspension droplet containing approximately 50 bacteria. In planta bacterial growth was assessed $24 \mathrm{~h}$ after incubation at alternating temperatures of 19 and $24^{\circ} \mathrm{C}$ during night $(16 \mathrm{~h})$ and day $(8 \mathrm{~h})$ conditions (stage $0)$. Inoculated leaves were dried to eliminate the inoculation

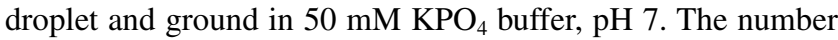
of bacteria present in the resulting extract was determined by serial dilutions on LB plates. The bacterial numerations were performed in at least three independent experiments. A linear regression model where numeration has been $\log _{10}$ transformed to normalize the data was carried out to assess the effect of mutations compared with the wild-type strain as reference. Ef- 
fect of a mutation was considered to be significant when the corresponding parameter in the regression was significantly different from $0(P$ value $<0.05)$.

\section{ACKNOWLEDGMENTS}

We thank G. Effantin for her assistance with some experiments, L. Desquilbert for his assistance with statistical analysis, G. Condemine for reading the manuscript, and the members of the Erwinia groups in Lyon and Paris for their helpful discussions. We acknowledge members of the International Erwinia Consortium for the exchange of unpublished data concerning the E. chrysanthemi 3937 genome. This work was supported by grants from the Centre National de la Recherche Scientifique and the Ministère de l'Education Nationale et de la Recherche and was initiated with the Programme Microbiologie 2003 (ACIM-2-17).

\section{LITERATURE CITED}

Aslanidis, C., Schmid, K., and Schmitt R. 1989. Nucleotide sequences and operon structure of plasmid-borne genes mediating uptake and utilization of raffinose in Escherichia coli. J. Bacteriol. 171:6753-6763.

Bardonnet, N., and Blanco, C. 1992. 'uidA-antibiotic-resistance cassettes for insertion mutagenesis, gene fusions and genetic constructions. FEMS (Fed. Eur. Microbiol. Soc.) Microbiol. Lett. 72:243-247.

Bausch, C., Peekhaus, N., Utz, C., Blais, T., Murray, E., Lowary, T., and Conway, T. 1998. Sequence analysis of the GntII (subsidiary) system for gluconate metabolism reveals a novel pathway for L-idonic acid catabolism in Escherichia coli. J. Bacteriol. 180:3704-3710.

Bell, K. S., Sebaihia, M., Pritchard, L., Holden, M. T., Hyman, L. J., Holeva, M. C., Thomson, N. R., Bentley, S. D., Churcher, L. J., Mungall, K., Atkin, R., Bason, N., Brooks, K., Chillingworth, T., Clark, K., Doggett, J., Fraser, A., Hance, Z., Hauser, H., Jagels, K., Moule, S., Norbertczak, H., Ormond, D., Price, C., Quail, M. A., Sanders, M., Walker, D., Whitehead, S., Salmond, G. P., Birch, P. R., Parkhill, J., and Toth, I. K 2004. Genome sequence of the enterobacterial phytopathogen Erwinia carotovora subsp. atroseptica and characterization of virulence factors. Proc. Natl. Acad. Sci. U.S.A. 101:11105-11110.

Chapuy-Regaud, S., Ogunniyi, A. D., Diallo, N., Huet, Y., Desnottes, J. F., Paton, J. C., Escaich, S., and Trombe, M. C. 2003. RegR, a global LacI/GalR family regulator, modulates virulence and competence in Streptococcus pneumoniae. Infect. Immun. 71:2615-2625.

Chouikha, I., Germon, P., Brée, A., Gilot, P., Moulin-Schouleur, M., and Schouler C. 2006. A selC-associated genomic island of the extraintestinal avian pathogenic Escherichia coli strain BEN2908 is involved in carbohydrate uptake and virulence. J. Bacteriol. 188:977-987.

Colmer, J. A., and Hamood, A. N. 1998. Characterization of ptxS, a Pseudomonas aeruginosa gene which interferes with the effect of the exotoxin A positive regulatory gene, ptxR. Mol. Gen. Genet. 258:250-259.

Coutinho, P. M., Deleury, E., Davies, G. J., and Henrissat, B. 2003. An evolving hierarchical family classification for glycosyltransferases. J. Mol. Biol. 328:307-317.

Delangle, A., Prouvost, A.-F., Cogez, V., Bohin, J.-P., Lacroix, J.-M., and Hugouvieux Cotte-Pattat, N. 2007. Characterization of the Erwinia chrysanthemi gan locus involved in galactan catabolism. J. Bacteriol. 189:7053-7061.

Dellagi, A., Rigault, M., Segond, D., Roux, C., Kraepiel, Y., Cellier, F., Briat, J.-F., Gaymard, F., and Expert, D. 2005. Siderophore-mediated up-regulation of Arabidopsis ferritin expression in response to Erwinia chrysanthemi infection. Plant J. 43:262-272.

Giammarinaro, P., and Paton, J. C. 2002. Role of RegM, a homologue of the catabolite repressor protein CcpA, in the virulence of Streptococcus pneumoniae. Infect. Immun. 70:5454-5461.

Hugouvieux-Cotte-Pattat, N. 2004. The RhaS activator controls the Erwinia chrysanthemi 3937 genes rhiN, rhiT and rhiE involved in rhamnogalacturonan catabolism. Mol. Microbiol. 51:1361-1374.

Hugouvieux-Cotte-Pattat, N., Dominguez, H., and Robert-Baudouy, J. 1992. Environmental conditions affect the transcription of the pectinases gene of Erwinia chrysanthemi 3937. J. Bacteriol. 174:7807-7018.

Hugouvieux-Cotte-Pattat, N., Condemine, G., Nasser, W., and Reverchon, S. 1996. Regulation of pectinolysis in Erwinia chrysanthemi. Annu. Rev. Microbiol. 50:213-257.

Jefferson, R. A., Kavanagh, T. A., and Bevan, M. W. 1987. GUS fusions:
Beta-glucuronidase as a sensitive and versatile gene fusion marker in higher plants. EMBO (Eur. Mol. Biol. Organ.) J. 6:3901-3907.

Lebeau, A., Reverchon, S., Gaubert S., Kraepiel Y., Simon-Cote E., Nasser W., and Van Gijsegem, F. 2008. The GacA global regulator is required for the appropriate expression of Erwinia chrysanthemi 3937 pathogenicity genes during plant infection. Environ. Microbiol. 10:545-559.

Lewis, M. 2005. The Lac repressor. C. R. Biol. 328:521-548.

Masclaux C., Hugouvieux-Cotte-Pattat N., and Expert, D. 1996. Iron is a triggering factor for differential expression of Erwinia chrysanthemi strain 3937 pectate lyases in pathogenesis of African Violets. Mol Plant-Microbe Interact. 9:198-205.

Miller, J. H. 1972. A Short Course in Bacterial Genetics: A Laboratory Manual and Handbook for Escherichia coli and Related Bacteria. Cold Spring Harbor Laboratory Press, Cold Spring Harbor, NY, U.S.A.

Nasser W., Faelen M., Hugouvieux-Cotte-Pattat N., and Reverchon S. 2001. Role of the nucleoid-associated protein H-NS in the synthesis of virulence factors in the phytopathogenic bacterium Erwinia chrysanthemi Mol. Plant-Microbe Interact. 14:10-20.

Ramseier, T. M., Bledig, S., Michotey, V., Feghali, R., and Saier, M. H. 1995. The global regulatory protein FruR modulates the direction of carbon flow in Escherichia coli. Mol. Microbiol. 16:1157-1169.

Resibois, A., Colet, M., Faelen, M., Schoonejans, T., and Toussaint, A. 1984. Phi-EC2, a new generalized transducing phage of Erwinia chrysanthemi. Virology 137:102-112.

Reverchon, S., Nasser, W., and Robert-Baudouy, J. 1991. Characterization of $k d g R$, a gene of Erwinia chrysanthemi regulating pectin degradation. Mol. Microbiol. 5:2203-2216.

Reverchon, S., Nasser, W., and Robert-Baudouy, J. 1994. pecS, a locus controlling pectinase, cellulase and blue pigment production in Erwinia chrysanthemi. Mol. Microbiol. 11:1127-1139.

Reverchon, S., Expert, D., Robert-Baudouy J., and Nasser, W. 1997. The cyclic AMP receptor protein is the main activator of pectinolysis genes in Erwinia chrysanthemi. J. Bacteriol. 179:3500-3508.

Reverchon, S., Rouanet, C., Expert, D., and Nasser, W. 2002. Characterization of indigoidine biosynthetic genes in Erwinia chrysanthemi and role of this blue pigment in pathogenicity. J. Bacteriol. 184:654-665.

Rodionov, D. A., Gelfand, M. S., and Hugouvieux-Cotte-Pattat, N. 2004. Comparative genomics of the $\mathrm{KdgR}$ regulon in Erwinia chrysanthemi 3937 and other gram-negative bacteria. Microbiology 150:3571-3590.

Roeder, D. L., and Collmer, A. 1985. Marker-exchange mutagenesis of a pectate lyase isozyme gene in Erwinia chrysanthemi. J. Bacteriol. 164:51-56

Sambrook, J. E., Fritsch, F., and Maniatis, T. 1989. Molecular Cloning: A Laboratory Manual. Cold Spring Harbor Laboratory Press, Cold Spring Harbor, NY, U.S.A.

Sepulchre, J. A., Reverchon, S., and Nasser, W. 2007. Modeling the onset of virulence in a pectinolytic bacterium. J. Theor. Biol. 244:239-257.

Surgey, N., Robert-Baudouy, J., and Condemine, G. 1996. The Erwinia chrysanthemi pecT gene regulates pectinase gene expression. J. Bacteriol. 178:1593-1599.

Swanson, B. L., Hager, P., Phibbs, P., Ochsner, U., Vasil, M. L., and Hamood, A. N. 2000. Characterization of the 2-ketogluconate utilization operon in Pseudomonas aeruginosa PAO1. Mol. Microbiol. 37:561-573.

Titgemeyer, F., Jahreis, K., Ebner, R., and Lengeler, J. W. 1996. Molecular analysis of the $s c r A$ and $s c r B$ genes from Klebsiella pneumoniae and plasmid pUR400, which encode the sucrose transport protein Enzyme II Scr of the phosphotransferase system and a sucrose-6-phosphate invertase. Mol. Gen. Genet. 250:197-206.

Yang, S., Peng, Q., Zhang, Q., Yi, X., Choi, C. J., Reedy, R. M., Charkowski, A. O., and Yang, C. H. 2008. Dynamic regulation of GacA in type III secretion, pectinase gene expression, pellicle formation, and pathogenicity of Dickeya dadantii (Erwinia chrysanthemi 3937). Mol. Plant-Microbe Interact. 21:133-142.

Yoshida, K., Yamaguchi, M., Ikeda, H., Omae, K., Tsurusaki, K., and Fujita, Y. 2004. The fifth gene of the iol operon of Bacillus subtilis, iolE, encodes 2-keto-myo-inositol dehydratase. Microbiology 150:571-580.

\section{AUTHOR-RECOMMENDED INTERNET RESOURCES}

J. Craig Venter Institute genome sequencing project: www.tigr.org/tdb/mdb/mdbinprogress.html

Wisconsin School of Veterinary Medicine Genome-Evolution Laboratory: asap.ahabs.wisc.edu/genome-evolution-laboratory 